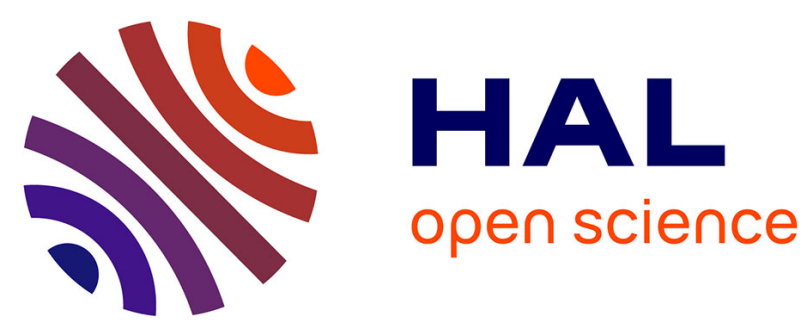

\title{
Diagnosis of testicular carcinoma in situ, (intratubular- and micro-invasive) seminoma and embryonal carcinoma using direct enzymatic alkaline phosphatase reactivity on frozen histological sections.
}

Hans Stoop, Wim Kirkels, Gert Dohle, Ad Gillis, Michael den Bakker, Katharina Biermann, J Wolter Oosterhuis, Leendert Looijenga

\section{To cite this version:}

Hans Stoop, Wim Kirkels, Gert Dohle, Ad Gillis, Michael den Bakker, et al.. Diagnosis of testicular carcinoma in situ, (intratubular- and micro-invasive) seminoma and embryonal carcinoma using direct enzymatic alkaline phosphatase reactivity on frozen histological sections.. Histopathology, 2011, 58 (3), pp.440. 10.1111/j.1365-2559.2011.03767.x . hal-00614748

\author{
HAL Id: hal-00614748 \\ https://hal.science/hal-00614748
}

Submitted on 16 Aug 2011

HAL is a multi-disciplinary open access archive for the deposit and dissemination of scientific research documents, whether they are published or not. The documents may come from teaching and research institutions in France or abroad, or from public or private research centers.
L'archive ouverte pluridisciplinaire HAL, est destinée au dépôt et à la diffusion de documents scientifiques de niveau recherche, publiés ou non, émanant des établissements d'enseignement et de recherche français ou étrangers, des laboratoires publics ou privés. 


\section{Histopathology}

Diagnosis of testicular carcinoma in situ, (intratubular- and micro-invasive) seminoma and embryonal carcinoma using direct enzymatic alkaline phosphatase reactivity on frozen histological sections.

\begin{tabular}{|r|l|}
\hline Journal: & Histopathology \\
\hline Manuscript ID: & HISTOP-02-10-0100.R2 \\
\hline Manuscript Type: & Original Article \\
\hline Date Submitted by the & 26-Apr-2010 \\
\hline Complete List of Authors: & $\begin{array}{l}\text { Stoop, Hans; Erasmus MC, Pathology } \\
\text { Kirkels, Wim; Erasmus MC, Pathology; Erasmus MC, Urology } \\
\text { Dohle, Gert; Erasmus MC, Urology } \\
\text { Gillis, Ad; Erasmus MC, Pathology } \\
\text { den Bakker, Michael; Erasmus MC, Pathology } \\
\text { Biermann, Katharina; Erasmus MC, Pathology } \\
\text { Oosterhuis, J; Erasmus MC, Pathology } \\
\text { Looijenga, Leendert; Erasmus MC, Pathology }\end{array}$ \\
\hline Keywords: & $\begin{array}{l}\text { testis sparing surgery, alkaline phosphatase, germ cell tumors } \\
\text { frozen tissue, diagnosis }\end{array}$ \\
\hline \hline
\end{tabular}

\section{今 ScholarONE" \\ Manuscript Central}




\section{Diagnosis of testicular carcinoma in situ, \\ (intratubular- and micro-invasive) seminoma and embryonal carcinoma using direct enzymatic alkaline phosphatase reactivity on frozen histological sections}

Hans Stoop ${ }^{1}$, Wim Kirkels², M.D., Gert R. Dohle ${ }^{2}$, M.D., Ph.D, Ad. J.M. Gillis $^{1}$, Michael A. den Bakker ${ }^{1}$, M.D. Ph.D., Katharina Biermann ${ }^{1}$, M.D., J. Wolter Oosterhuis ${ }^{1}$, M.D., Ph.D., Leendert H.J. Looijenga ${ }^{1}$, Ph.D.

${ }^{1}$ Departments of Pathology and ${ }^{2}$ Urology, Erasmus MC-University Medical Center Rotterdam, Josephine Nefkens Institute, Daniel den Hoed Cancer Center, Rotterdam, The Netherlands

Key words: alkaline phosphatase reactivity; carcinoma in situ; direct diagnosis; embryonal carcinoma; frozen tissue; seminoma; surgical intervention; testicular tumors

Running title: Alkaline phosphatase in germ cell tumors.

Correspondence to:

Professor L.H.J. Looijenga, Ph.D.

Department of Pathology, Erasmus MC-University Medical Center Rotterdam, Josephine Nefkens Institute, Building Be, Room 430b, P.O. Box 2040, 3000 CA Rotterdam, The Netherlands

Phone: +31 10 7044329; Fax: +31 107044365

Email: l.looijenga@erasmusmc.nl 


\section{ABSTRACT}

Aims: Testis-sparing surgery might benefit quality of life, but can only be applied with histological examination for the presence of invasive germ cell tumor components, and the precursor carcinoma in situ (CIS). Currently, diagnosis is based on paraffinembedded tissue, therefore a delay in further surgery is mostly unavoidable.

Methods and Results: A total of 4,093 snap frozen samples and matched paraffinembedded tissue of 1,500 patients were included. Besides standard $\mathrm{H} \&$ e staining, the direct enzymatic alkaline phosphatase reactivity (dAP) test (duration 15 minutes). was applied on frozen sections, while $\mathrm{H} \&$ e and immunohistochemistry for detection of OCT3/4, AFP, hCG and cytokeratin was done on the paraffin-embedded slides. Endothelial cells served as control for the dAP test. A positive staining was found in all CIS ( $n=965)$, seminoma $(n=1035)$, and embryonal carcinoma $(n=584)$, either intratubular, micro-invasive or invasive. Differentiated non-seminomas ( $n=1238$ ) showed variable staining. No staining was identified in spermatocytic seminomas (n $=5)$, testicular lymphomas $(n=42)$, testicular rhabdomyosarcomas $(n=7)$, Leydig cell tumors ( $n=31$ ), Sertoli-cell-only nodules $(n=4)$, (epi)dermoid cyst $(n=16)$, normal testicular parenchyma $(n=116)$, testicular torsion $(n=32)$ and inflammation of the epididymis $(n=19)$. The dAP test results matched $H$ \& e stained parallel sections, as well paraffin-embedded tissue analysis, including immunohistochemistry.

Conclusion: The dAP test is informative, reproducible, and easy tool to diagnose CIS, (intratubular and micro-invasive) seminoma and embryonal carcinoma on frozen tissue sections, being of great value in the context of sparing surgery. 


\section{INTRODUCTION}

Testicular tumors are a heterogeneous group of lesions, with different origin and pathogenesis. These include Leydig cell tumors, Sertoli cell tumors, lymphomas, sarcomas, and various types of tumors originating from the germ cell lineage [1]. Based on clinical and patho-biological criteria testicular germ cell tumors can be subdivided into three categories, i.e., teratomas and yolk sac tumors of neonates and infants (type I), seminomas and nonseminomas, referred to as TGCTs (type II) and spermatocytic seminomas (type III). In addition, there are benign teratomatous lesions with the histology of somatic tissue, including (epi)dermoid cysts Although TGCTs are rare in the general population, with an incidence between 6 and 11 per 100.000 in Caucasian males, they represent the most common cancer in men aged between 15 and 45 years and the incidence is still rising [2]. High success rates in clinical management of TGCTs have been achieved using a combination of surgery, irradiation and chemotherapy [3]. In fact, standard care for therapy for TGCTs is radical orchiectomy, which may be combined with irradiation and/or cisplatin-based chemotherapy, depending on the histology of the tumor, as well as the disease stage. In the diagnostic work up, the presence of elevated serum markers $\alpha$ foetoprotein (AFP), $\beta$-human chorion gonadotropin ( $\beta$-HCG) and/or lactate dehydrogenase (LDH) is informative. However, in present clinical practice a tumor in a testis is in itself enough reason to perform a radical orchiectomy, without a histological diagnosis of the testicular lesion. Recently, more attention is given to the possibility of testis sparing surgery in specific patients. This alternative procedure may be of interest for patients with a bilateral TGCT or an affected monotestis, in whom standard care would result in complete castration and life long dependence on hormone substitution (testosterone replacement) [4]. To avoid these sequelae, organ sparing surgery might be an option, in which the tumor is enucleated and the normal appearing testis parenchyma is preserved $[5,6]$. Other patients that may benefit from such an approach are those without elevated serum markers and a small, possibly benign tumor [7]. However, a limitation is that no distinction can be made between a benign and a malignant lesion using the available imaging techniques, like ultrasonography or magnetic resonance imaging. Therefore, by definition, exploratory surgery is required and frozen section analysis of tumor tissue. In fact, histological investigation should be done of the lesion and its adjacent parenchyma. 
Carcinoma In Situ (CIS), also known as Intratubular Germ Cell Neoplasia Unclassified (IGCNU) [8], or Testicular Intratubular Neoplasia (TIN), is the precursor of all TGCTs [9]. Identification of CIS is sufficient for the diagnosis of a TGCT, which is by definition malignant. CIS is present in the majority of patients with an invasive TGCT, more frequently in patients with nonseminomas than with seminomas, which is likely related to the immune response [10]. It is reported that $70 \%$ of the patients with CIS will develop an invasive tumor within 7 years, which is extrapolated to $100 \%$ at 10 years [11]. Of importance is the fact that CIS can be effectively treated by local low dose irradiation with preservation of hormonal function of the testis in most cases [11]. In daily practice, CIS is diagnosed using (formalin-, Stieve's- or Bouin-) fixed, paraffin-embedded tissue, preferably supported by immunohistochemical staining, for example OCT3/4 [12-15], or C-KIT (CD117) and PLAP [8]. The required time to diagnose CIS, based on paraffin-embedded tissue, possibly supported by immunohistochemistry, precludes its application as an intra-operative procedure. Therefore, if malignant cells are found in the adjacent parenchyma, a second intervention, usually surgical, is required. Alternatively, frozen tissue diagnosis might be applied to determine the presence of CIS, as well as invasive tumor components, like (intratubular - and micro-invasive) seminoma or embryonal carcinoma. The problem is that the morphology of frozen $\mathrm{H}$ and e stained sections is often not sufficient to reliably diagnose CIS. This shortcoming of frozen section diagnosis could be compensated for with a specific marker that can be applied on frozen section intra-operatively. Alkaline phosphatase is such a marker.

Alkaline phosphatases are membrane-bound glycoproteins occurring in various forms and different tissues, which are encoded by different genes, i.e., Tissue Non specific Alkaline Phosphatase (TNAP), Tissue Specific Alkaline Phosphatase (TSAP), being Placental-, Intestine- and Germ Cell Alkaline Phosphatse (PLAP and GCAP) [16]. No specific antibodies against all these various isozymes are currently available. Alkaline phosphatase is present in migrating primordial germ cells (PGCs), and in gonocytes as well as in prespermatogonia in embryonal gonads [17]. In fact, this enzymatic activity was initially used to identify mouse PGCs during normal embryogenesis [18, 19]. In normal testis parenchyma of the adolescents and adults, no endogeneous activity of alkaline phosphatase is present, except in the endothelial cells of small blood vessels [20]. It is known that PLAP and GCAP is abundantly expressed in seminoma and embryonal carcinoma 
$[21,22]$. Since the enzyme is also present in CIS, it may be applied as a marker for the early diagnosis of TGCTs [17].

Here we present the application of a direct histochemical detection of alkaline phosphatase enzyme reactivity, which detects the activity of all enzymes, to diagnose CIS, (intratubular and micro-invasive) seminoma and embryonal carcinoma on frozen tissue sections. It has additional value compared to standard $\mathrm{H} \& \mathrm{e}$ staining, and is comparable to immunohistochemical detection of OCT3/4. The method is simple, cheap, quick and highly reproducible, devoid of false negative and false positive findings. Unequivocal demonstration of presence or absence of $\mathrm{CIS}$ in frozen sections during operation will support surgical decision making, in particular to avoid a second surgical intervention and to recognize situations where testis sparing surgery should be performed. For this purpose, the dAP test will be highly informative. 


\section{MATERIALS AND METHODS}

Use of tissues for scientific purposes as included in this study was approved by an institutional review board (MEC 02.981 and CCR2041), and the samples were used according to the "Code for Proper Secondary Use" (FMWV) (version 2002).

\section{Primary tissue handling:}

The material used was handled by routine procedures. Upon incision of the specimen, a digital image was generated, and possibly heterogeneity of the specimen identified. Representative parts of the tumor area(s) (possible including different elements) and adjacent parenchyma were cut and fixed in $10 \%$ buffered formalin for maximum 24 hours, and subsequently embedded in paraffin. Parallel areas of both the tumor and parenchyma were cut and snap frozen in liquid nitrogen. This according to special requirements. Small fresh biopsies need to be prepared as fast as possible after surgical intervention. The biopsies were placed on a small piece of thin cork, covered with a small piece of wet filter paper, after which they were directly frozen in liquid nitrogen. Larger pieces of testis tissue were snap frozen, without the cork support, again in liquid nitrogen. In addition, special care has to be taken in cutting the sections: under no circumstances should the frozen tissue be thawed, which will compromise morphology and enzyme-histochemical staining, and thus the interpretation of the slides.

The snap frozen samples were investigated for histology using both the $\mathrm{H}$ \& e staining and the dAP test (see below) on parallel slides, allowing optimal comparison. The diagnosis made based on the snap frozen sections stained with either $\mathrm{H} \& \mathrm{e}$ and the dAP test were compared directly. The pathologist (JWO) first studied the $\mathrm{H} \&$ e stained sections(s) and decided whether CIS and/or invasive tumor components were present. This was confirmed for CIS, (intratubular and micro-invasive) seminoma and embryonal carcinoma based on the dAP stained slides. In addition, the findings on the frozen samples were compared to the diagnosis made on the formalin-fixed, paraffin-embedded tissues. Therefore again the $\mathrm{H}$ \& e staining as done, as well as immunohistochemistry using antibodies specifically detecting OCT3/4, AFP, hCG, and cytokeratin (CAM5.2). All tumors were diagnosed according to the WHO classification. 
Direct alkaline phosphatase reactivity detection:

Frozen tissue sections of $5 \mu \mathrm{m}$ thickness were air dried (room temperature for at least 30 seconds), and fixed for 10 seconds in 100\% acetone. Subsequently, the slides were air dried for 30 seconds and incubated for 5-10 minutes in $60 \mathrm{ml} \mathrm{Tris} \mathrm{HCl}$ pH8.4 (0,2 M) with $20 \mathrm{mg}$ Fast Red (Sigma; F8764) and $20 \mathrm{mg}$ Naphtol AS-MX phosphate salt (Sigma; N5000). After washing in running tap water the slides were fixed for 30 seconds in 10\% buffered formalin and counterstained with hematoxylin. Subsequently they were covered with an aqueous mounting medium (Imsol-mount; Klinipath; 4059), and visually inspected, after which they could be stored in the archive. 


\section{RESULTS:}

During a period of more than 15 years of collecting primary testicular tumors in close collaboration with Pathologists and Urologists in the South-Western part of the Netherlands, a large archive has been established. This tissue bank contains more than 1,500 tumors from individual patients, of which frozen tissue as well as (matched) formalin-fixed, paraffin-embedded tissue is available. Representative slides of all frozen tissue samples were routinely stained using $\mathrm{H}$ \& $\mathrm{e}$ and investigated for $\mathrm{dAP}$, of which the findings showed no discrepancies. However, identification of CIS was more unequivocal using the dAP test. This was especially the case when only a relatively limited number of seminiferous tubules contained CIS cells, and when the affected tubules also retained spermatogenesis (see below). In addition, the findings were compared to the observations made on the formalin-fixed paraffin-embedded tissues, which were also stained using $\mathrm{H}$ \& e and investigated by immunohistochemistry (see Materials and Methods section). All cases were examined by an experienced pathologist with a special interest in TGCTs (J.W.O.). All tumors were described in an standardized, authorized pathology report, in which various items were scored, including the presence of CIS, presence of the various invasive components, as well as intratubular variants (seminoma and embryonal carcinoma). Again no discrepancies between the various approaches were found. The results are summarized in the Table, as well as the diagnosis made. Representative examples are shown in the Figure.

Normal parenchyma and non-neoplastic conditions (normal parenchyma (Figure A), testicular torsion, and chronic inflammation) showed no alkaline phosphatase reactivity, with the consistent exception of endothelial cells. The same pattern was found in all spermatocytic seminomas (Figure B) and non-TGCTs (), testicular lymphoma (Figure C), rhabdomyosarcoma, Leydig cell tumor (Figure D), Sertoli cell-only-nodule, dermoid cysts and epidermoid cysts (Figure E). The endothelial cells, showing a positive staining, predominantly of the smaller vessels, served as a quality control for this enzymatic staining. In contrast to the consistent negative finding as indicated above, all CIS (Figure F and G) and (intratubular- and micro-invasive) seminoma (Figure $\mathrm{H}$ and $\mathrm{I}$ ) and embryonal carcinoma (Figure $\mathrm{J}$ and K) samples were positive. Interestingly, the CIS cells were not restricted to seminiferous tubules without spermatogenesis. The pre-invasive tumor cells are 
located on the basal membrane in the niche under the tight junctions between the Sertoli cells. Some cases did not contain CIS, which is due to the absence of testicular parenchyma available for analysis, because of the overgrowth of the tumor. The same staining pattern as in CIS is seen in intratubular seminoma, although in this case the seminiferous tubule is completely filled with tumor cells, and Sertoli cells may be completely absent. Upon invasive growth the staining pattern stays the same. A different pattern was observed in embryonal carcinoma, in which not every single cell is positive. In stead groups of tumor cells are defined by a polarized membranous staining for alkaline phosphatase. This pattern was similar for intratubular, micro-invasive and frankly invasive embryonal carcinoma. In contrast, a more heterogeneously staining pattern of the enzymatic reactivity was identified in the various differentiated nonseminomatous components, like yolk sac tumor (Figure $L$ ), choriocarcinoma (Figure $M$ ), teratoma (Figure $N$ ). However, identification of the $\mathrm{dAP}$ test is not required in these cases, because the diagnosis can be made based on histological investigation ( $\mathrm{H}$ \& e stained section) alone. Gonadoblastoma, which is the CIS-counterpart of the dysgenetic gonad [23, 24], also showed a positive staining for alkaline phosphatase (Figure O).

Recent examples illustrate the power of the method to guide intra-operative surgical decision making. In two cases the suspicious testis (based on physical examination and ultrasound analysis), was not removed because staining for alkaline phosphatase ruled out the presence of a TGCT or CIS. In another case CIS and a small seminoma were demonstrated in patient whose other testis was earlier removed for a TGCT. During operation it was decided to excise the seminoma and to spare the testicle to preserve its hormonal function. The remaining CIS was treated with local irradiation. The patient is under surveillance. In a 17 year-old boy an opportunity for testis sparing surgery was missed. Microscopical examination of the removed testis demonstrated a small epidermoid cyst (11 $\mathrm{mm}$ in diameter), lacking an invasive component or CIS, thus constituting a benign lesion. In this case testis sparing surgery could have been performed, if snap frozen analysis was done on both the tumor as well as the adjacent parenchyma to rule out the presence of CIS, (intratubular and micro-invasive) seminoma and embryonal carcinoma. 


\section{DISCUSSION}

Individualized treatment of cancer patients is becoming a major issue in current clinical practice. This is aimed at achieving optimal treatment success rates and at the same time reduction of treatment side effects, to ensure quality of life, both at short and long term. Although intra-operative frozen section examination is commonly applied in surgical management for various malignancies, its role in clinical management of testicular masses is still in its infancy. However, organ preserving surgery can be the preferred therapeutic intervention in some cases. These may include patients with a benign testicular lesion, as demonstrated by for example Heidenreich and coworkers in a series of 18 patients treated with enucleation of a benign tumor and analysis of frozen biopsies of the adjacent parenchyma [25]. In addition, an adenomatoid tumor of the testis was treated by testis sparing surgery after it was diagnosed as benign by intra-operative frozen section examination [26]. Moreover, a segmental testicular infarction, simulating a TGCT, was treated by partial orchiectomy after a frozen section diagnoses. [27].

Currently, standard treatment of a primary TGCT is radical orchiectomy, followed by additional treatment depending on the stage of the disease and characteristics of the tumor, being either irradiation or chemotherapy [3]. However, some patients might benefit from a more conservative surgical approach. This might prevent complete castration in case of patients with a tumor in a solitary testis, a bilateral testicular tumor, or a second testicular tumor after an initial unilateral orchiectomy. In fact, organ preserving surgery is not yet standard care in these patients [28, 29]. Furthermore, sufficient endocrine function of the remaining testicular parenchyma should remain after the operation. If organ preserving surgery is to be performed, detailed investigation of the adjacent testicular parenchyma is required to determine the presence of CIS, as well as (intratubular- and microinvasive) seminoma and embryonal carcinoma. The other histological elements are more easy to diagnose based on standard histological analysis. If CIS is histologically documented, adjuvant radiotherapy of the remaining testicular tissue is strongly recommended according to the management strategy for CIS in unilateral tumors [7]. If invasive tumor components are identified, orchiectomy must be considered. Histological examination is predominantly performed on fixed tissue, which benefits from optimally preserved morphology. This is significantly reduced using snap frozen tissue. 
The procedure described in this paper was investigated in a large prospective series of 1,500 patients, of which more than 4,000 frozen and matched formalin-fixed paraffin-embedded samples were investigated. The direct alkaline phosphatase staining (dAP) test, allows a fast and reliable identification of CIS, (intratubular, micro-invasive and invasive) seminoma and embryonal carcinoma on frozen tissue sections within 15 minutes after surgical removal. The absolute sensitivity and specificity of detection of the enzymatic alkaline phosphatase detection on frozen tissue, makes identification of CIS, seminoma or embryonal carcinoma highly reproducible compared to standard snap frozen tissue analysis based on $\mathrm{H} \& \mathrm{e}$ staining. The dAP test is able to detect even a single CIS cell in a seminiferous tubule with spermatogenesis, as well as limited number of CIS containing seminiferous tubules in a background of most unaffected tubules. This method, which includes an internal positive control, i.e., endothelial cells, which were present in all investigated samples, was as informative as the immunohistochemical detection of OCT3/4 on paraffin-embedded tissue, based on comparison of matched frozen and paraffin sections analysis of all cases (data not shown). In fact, no discrepancies were found between the diagnoses made using the two methods. In addition, the test can be easily implemented in routine clinical histopathology.

In conclusion, the dAP test we introduce is a valuable diagnostic tool in testis conserving surgery, allowing direct evaluation of the presence of CIS, seminoma or embryonal carcinoma. With the availability of this intra-operative test the development and implementation of testis sparing surgery is more feasible than thus far. Even so testis sparing surgery should be performed at a centre with sufficient experience in the management of this rare clinical situation [30]. However, some limitations must be kept in mind. Although CIS is found in most affected testicular parenchyma samples in case of a type II GCT, is can show a heterogeneous pattern. This patchy distribution can result in a false negative finding upon biopsy analysis, which is not influenced by either detection technique applied [16]. In this context it is of relevance that two independent surgical biopsies are recommended for detection of CIS in a normal-sized testis, each with a diameter of at least $3 \mathrm{~mm}$ [31]. However, although the risk will be small, the presence can never be absolutely excluded in case of a negative finding on biopsy material. Therefore proper size of the biopsy and subsequent handling and analysis are of great importance for optimal diagnosis. 


\section{References:}

[1] Oosterhuis J, Looijenga L. Testicular germ-cell tumours in a broader perspective. Nat Rev Cancer. 2005 Mar;5(3):210-22.

[2] Bergström R, Adami H-O, Mohner M, Zatonski W, Storm H, Ekbom A, et al. Increase in testicular cancer incidence in six European countries: a birth cohort phenomenon. J Natl Cancer Inst. 1996;88:727-33.

[3] Horwich A, Shipley J, Huddart R. Testicular germ-cell cancer. Lancet. 2006 Mar 4;367(9512):754-65.

[4] Ehrlich Y, Konichezky M, Yossepowitch O, Baniel J. Multifocality in Testicular Germ Cell Tumors. J Urol. 2009 Jan 15.

[5] Walsh C, Rushton HG. Diagnosis and management of teratomas and epidermoid cysts. Urol Clin North Am. 2000 Aug;27(3):509-18.

[6] Heidenreich A, L WE, Holtl W, Albers P, Kliesch S, Kohrmann KU, et al. Organ Sparing Surgery For Malignant Germ Cell Tumor of the Testis. J Urol. 2001;166(6):2161-5.

[7] Schmoll HJ, Souchon R, Krege S, Albers P, Beyer J, Kollmannsberger C, et al. European consensus on diagnosis and treatment of germ cell cancer: a report of the European Germ Cell Cancer Consensus Group (EGCCCG). Ann Oncol. 2004 Sep;15(9):1377-99.

[8] Woodward PJ, Heidenreich A, Looijenga LHJ, Oosterhuis JW, McLeod DG, Moller H. Testicular germ cell tumors. In: Eble JN, Sauter G, Epstein JI, Sesterhann IA, eds. World Health Organization Classification of Tumours Pathology and Genetics of the Urinary System and Male Genital Organs. Lyon: IARC Press 2004:217-78.

[9] Skakkebæk NE. Possible carcinoma-in-situ of the testis. Lancet. 1972:516-7.

[10] Oosterhuis JW, Kersemaekers AM, Jacobsen GK, Timmer A, Steyerberg EW, van Weeren PC, et al. Morphology of testicular parenchyma adjacent to germ cell tumours; an interim report. APMIS. 2003;111:32-42.

[11] Rorth M, Rajpert-de Meyts E, Skakkebæk NE, et al. Carcinoma in situ of the testis. Scan J Urol. 2000;205:166-86.

[12] Looijenga LHJ, Stoop H, De Leeuw PJC, De Gouveia Brazao CA, Gillis AJM, Van Roozendaal KEP, et al. POU5F1 (OCT3/4) identifies cells with pluripotent potential in human germ cell tumors. Cancer Res. 2003;63:2244-50.

[13] de Jong J, Stoop H, Dohle GR, Bangma CH, Kliffen M, van Esser JW, et al. Diagnostic value of OCT3/4 for pre-invasive and invasive testicular germ cell tumours. J Pathol. 2005 Jun;206(2):242-9.

[14] Van Casteren N, De Jong J, Stoop J, Steyerberg EW, De Bekker-Grob EW, Dohle GR, et al. Evaluation of testicular biopsies for Carcinoma in Situ: Immunohistochemistry is mandatory. Int J Androl. 2008;in press.

[15] van Casteren NJ, Boellaard WP, Dohle GR, Weber RF, Kuizinga MC, Stoop H, et al. Heterogeneous distribution of ITGCNU in an adult testis: consequences for biopsy-based diagnosis. Int J Surg Pathol. 2008 Jan;16(1):21-4.

[16] Millan JL, Fishman WH. Biology of human alkaline phosphatases with special reference to cancer. Crit Rev Clin Lab Sci. 1995;32(1):1-39.

[17] Hustin J, Collette J, Franchimont P. Immunohistochemical demonstration of placental alkaline phosphatase in various states of testicular development and in germ cell tumors. Int J Androl. 1987;10:29-35.

[18] D.G. M, Hertig AT, Adams EC, Danziger S. Histochemical observations on the germ cells of human embryos. Anat Rec. 1953 Oct;117(2):201-19.

[19] Chiquoine AD. The identification, origin, and migration of the primordial germ cells in the mouse embryo. Anat Rec. 1954 Feb;118(2):135-46.

[20] Roelofs H, Manes T, Millan JL, Oosterhuis JW, Looijenga LHJ. Heterogeneity in alkaline phosphatase isozyme expression in human testicular germ cell tumors. An enzyme/immunohistochemical and molecular analysis. J Pathol. 1999;189:236-44.

[21] Koshida K, Wahren BE. Enzymatic heterogeneity of seminomas. Clin Chim Acta. 1990;186:255-64. 
[22] Koshida K, Uchibayashi T, Hisazumi H. Characterization of seminoma-derived placental-like alkaline phosphatase. Urol Int. 1991;47:96-9.

[23] Cools M, Drop SL, Wolffenbuttel KP, Oosterhuis JW, Looijenga LH. Germ cell tumors in the intersex gonad: Old paths, new directions, moving frontiers. Endocr Rev. 2006 May $30 ; 27: 468-84$.

[24] Hersmus R DLH, Wolffenbuttel KP, Drop SLS, Oosterhuis JW, Cools M, Looijenga LHJ. New insights into type II Germ Cell Tumor pathogenesis based on the studies of patients with various forms of Disorders of Sex Development (DSD). Mol and Cell Endocrinology. 2008;291:1-10.

[25] Heidenreich A, Bonfig R, Derschum W, Von Vietsch H, Wilbert DM. A conservative approach to bilateral testicular germ cell tumors. J Urol. 1995;153:10-3.

[26] Mitsui Y, Ueda Y, Suzuki T, Shincho M, Higuchi Y, Qiu J, et al. [A case of adenomatoid tumor of the testis treated by testis-sparing surgery: a case report]. Hinyokika Kiyo. 2008 May;54(5):383-6.

[27] Hidalgo J, Rodriguez A, Canalias J, Muntane MJ, Huerta MV, Carrasco N, et al. Segmental testicular infarction vs testicular tumour: the usefulness of the excisional frozen biopsy. Arch Esp Urol. 2008 Jan-Feb;61(1):92-3.

[28] Heidenreich A, HoltI W, Albrecht W, Pont J, Engelmann UH. Testis-preserving surgery in bilateral testicular germ cell tumours. Br J Urol. 1997;79(2):253-7.

[29] Steiner H, Holtl L, Maneschg C, Berger AP, Rogatsch H, Bartsch G, et al. Frozen section analysis-guided organ-sparing approach in testicular tumors: technique, feasibility, and long-term results. Urology. 2003 Sep;62(3):508-13.

[30] Passman C, Urban D, Klemm K, Lockhart M, Kenney P, Kolettis P. Testicular lesions other than germ cell tumours: feasibility of testis-sparing surgery. BJU Int. 2009 Feb;103(4):488-91.

[31] Dieckmann KP, Kulejewski M, Pichlmeier U, Loy V. Diagnosis of contralateral testicular intraepithelial neoplasia (TIN) in patients with testicular germ cell cancer: systematic two-site biopsies are more sensitive than a single random biopsy. Eur Urol. 2007;51:175-183. 


\section{Legends to the Figure}

Examples of the direct alkaline phosphatase staining on frozen tissue sections of: $A$ ) normal adult testis parenchyma; B) spermatocytic seminoma; C) lymphoma; D) Leydig cell tumor; E) epidermoid cyst, all showing only positive staining in endothelail cells; F and G) carcinoma in situ (CIS) (parallel H and E staining as insert, * position normal tubule); H) intratubular seminoma; I) invasive seminoma; J) intratubular embryonal carcinoma; K) invasive embryonal carcinoma; all showing a positive staining with a pattern as described in the text; L) yolk sac tumor; $M$ ) choriocarcinoma; N) teratoma; O) gonadoblastoma (showing a similar staining pattern as CIS). All images are at a magnification of 100x, except $F$, being at 200x. 


\section{Table}

Results of direct alkaline phosphatase staining on frozen tissue sections of over 4,000 samples from 1,500 patients. The number of cases investigated (= tested) and positive results (\%) are indicated.

Benign lesions: Histology

Normal parenchyma

Torsio

Chronic inflammation

Sertoli cell-only-nodule

\begin{tabular}{|c|c|}
\hline Tested & Positive \\
\hline 116 & 0 \\
\hline 32 & 0 \\
\hline 19 & 0 \\
\hline 4 & 0 \\
\hline
\end{tabular}

Non TGCTs:

Spermatocytic seminoma

Lymphoma

Rhabdomyosarcoma

Leydig cell tumor

(Epi)Dermoid cyste

$\begin{array}{rl}5 & 0 \\ 42 & 0 \\ 7 & 0 \\ 31 & 0 \\ 16 & 0\end{array}$

\section{TGCTs and precursor:}

$\begin{array}{lrl}\text { Carcinoma in situ } & 965 & 100 \\ \text { Intratubular seminoma } & 244 & 100 \\ \text { Seminoma } & 791 & 100 \\ \text { Intratubular embryonal carcinoma } & 71 & 100 \\ \text { Embryonal carcinoma } & 513 & 100 \\ \text { Yolk sac tumor } & 402 & * \\ \text { Choriocarcinoma } & 41 & * \\ \text { Teratoma } & 795 & *\end{array}$

* a heterogeneous staining pattern was identified, with both positive and negative regions, even within a single tumor. This observation does not negatively influence the power of the dAP method to detect CIS, seminoma and embryonal carcinoma, both intratubular, micro-invasive and invasive. 


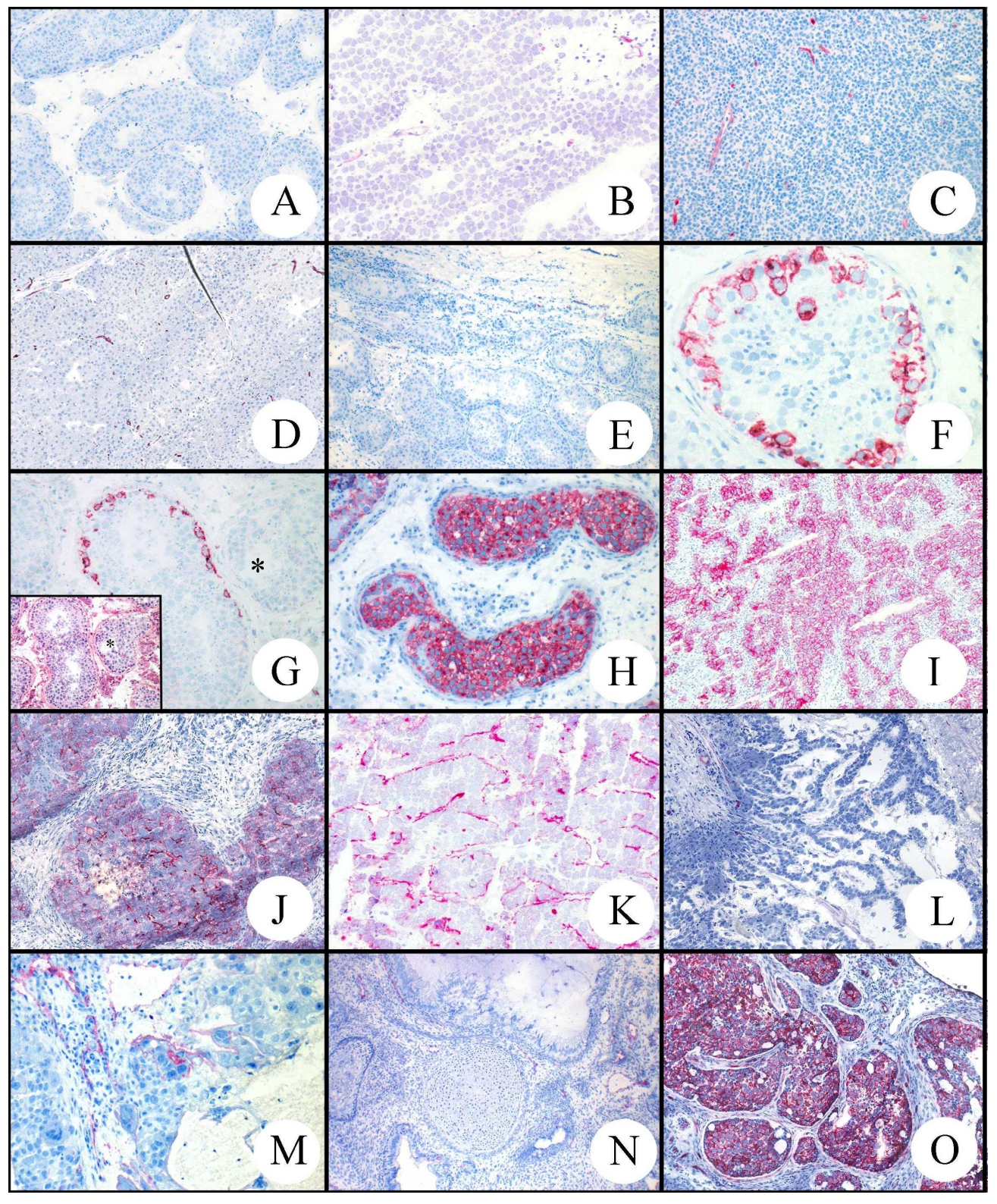

$608 \times 735 \mathrm{~mm}(96 \times 96$ DPI $)$ 